Article

\title{
Ostrowski Type Inequalities Involving $\psi$-Hilfer Fractional Integrals
}

\author{
Yasemin Basci ${ }^{1, *}$ (1) and Dumitru Baleanu ${ }^{2,3}$ (1) \\ 1 Department of Mathematics, Faculty of Arts and Sciences, Bolu Abant Izzet Baysal University, 14280 Golkoy, \\ Bolu, Turkey \\ 2 Department of Mathematics, Faculty of Arts and Sciences, Çankaya University, 06530 Ankara, Turkey \\ 3 Institute of Space Sciences, 077125 Bucharest-Magurele, Romania \\ * Correspondence: basci_y@ibu.edu.tr
}

Received: 29 June 2019; Accepted: 16 August 2019; Published: 21 August 2019

\begin{abstract}
In this study we introduce several new Ostrowski-type inequalities for both left and right sided fractional integrals of a function $g$ with respect to another function $\psi$. Our results generalized the ones presented previously by Farid. Furthermore, two illustrative examples are presented to support our results.
\end{abstract}

Keywords: fractional calculus; fractional integrals; Ostrowski type inequality

MSC: 26A24; 26A33; 26B15

\section{Introduction and Preliminaries}

Since 1695 [1-3], fractional calculus has been studied by many researchers from both theoretical and applied viewpoints [4,5]. Particularly, fractional calculus is used to generalize classical inequalities. Studies involving integral inequalities are important in several areas such as mathematics, physics, chemistry, biology, engineering and others [6-15]. We recall that there are many definitions of fractional operators, including Riemann-Liouville (RL), Hadamard, Liouville, Weyl (see [16-19]). From such fractional integrals, one can obtain generalizations of the inequalities: Hadamard, Hermite-Hadamard, Hardy, Opial, Gruss, and Montgomery, among others [20-32].

We mention that the following inequality was developed by Ostrowski [33]:

Theorem 1. Let $g: I \rightarrow \mathbb{R}$ be a mapping differentiable in $I^{\circ}$ such that $I$ is an interval in $\mathbb{R}, I^{\circ}$ is the interior of I and $a_{1}, b_{1} \in I^{\circ}, a_{1}<b_{1}$. If $\left|g^{\prime}(\xi)\right| \leq M$ for all $\xi \in\left[a_{1}, b_{1}\right]$, then the integral inequality holds

$$
\left|g(x)-\frac{1}{b_{1}-a_{1}} \int_{a_{1}}^{b_{1}} g(\xi) d \xi\right| \leq\left[\frac{1}{4}+\frac{\left(x-\frac{a_{1}+b_{1}}{2}\right)^{2}}{\left(b_{1}-a_{1}\right)^{2}}\right]\left(b_{1}-a_{1}\right) M,
$$

for all $x \in\left[a_{1}, b_{1}\right]$.

In the literature, the inequality (1) is called the Ostrowski inequality, see [34]. This inequality has a great importance while studying the error bounds of different numerical quadrature rules. In recent years, such inequalities have been generalized and developed by many researchers. Various authors obtained new Ostrowski-type inequalities for different fractional operators, see [16-19,35-47] and the references therein.

In 2009, Anastassiou et al. [20] obtained Montgomery identities for fractional integrals and a generalization for double fractional integrals. For fractional integrals they discussed both Ostrowski 
and Grüss inequalities. In 2010, Alomari and Darus [36] presented some Ostrowski-type inequalities for the class of convex (or concave) functions. In 2012, Set [41] obtained some new fractional Ostrowski-type inequalities. In the same year, Liu [40] established some Ostrowski-type inequalities involving RL fractional integrals for the $h$-convex function. His results are generalizations of $[41,42]$. He also provided new estimates on Ostrowski-type inequalities for fractional integrals.

In 2013, Yue [38] obtained Ostrowski inequalities for both fractional integrals and associated fractional integrals. In 2014, Aljinević [16] studied Montgomery identities for fractional integrals of a function $f$ with respect to another function $g$. Also, he gave the Ostrowski inequality for fractional integrals for functions whose first derivatives belong to $L_{p}$ spaces. In the same year, Yildirım and Kirtay [46] established new generalizations for Ostrowski inequalities by using the generalized RL fractional integral.

Y1ldiz et al. [47] used the RL fractional integrals to obtain several new generalizations of Ostrowski type inequalities. Farid [35] found a new version of Ostrowski type inequalities in a very simple way for RL fractional integrals. He also derived some related results. Recently, Dragomir studied several generalizations of the Ostrowski type integral inequality involving RL fractional integrals of bounded variation: Hölder and Lipschitzian functions, see [17-19]. In 2018, Yaldız and Set [45] obtained some new Ostrowski type inequalities for generalized fractional integral operators.

Recently, Sousa and Oliveira [43] introduced the left and right sided fractional integrals and the so-called $\psi$-Hilfer fractional derivative with respect to another function. They studied Gronwall inequalities and the Cauchy-type problem by means of the $\psi$ - Hilfer operator in [44]. Consequently, they opened a window for new applications.

The following definitions are special approaches for when the kernel is unknown, involving a function $\psi$. Let $\alpha_{1}>0$ and $I=\left[a_{1}, b_{1}\right]$ be a finite or infinite interval. Also, let the function $g$ be integrable defined on $I$, and the function $\psi$ be increasing and positive monotone on $\left(a_{1}, b_{1}\right]$, having a continuous derivative $\psi^{\prime}(x)$ on $\left(a_{1}, b_{1}\right)$.

The expressions of the left sided and right sided fractional integrals of a function $g$ with respect to another function $\psi$ can be seen $[4,5]$, respectively:

$$
I_{a_{1}^{+}}^{\alpha_{1} ; \psi} g(x):=\frac{1}{\Gamma\left(\alpha_{1}\right)} \int_{a_{1}}^{x} \psi^{\prime}(\xi)(\psi(x)-\psi(\xi))^{\alpha_{1}-1} g(\xi) d \xi
$$

and

$$
I_{b_{1}^{-}}^{\alpha_{1} ; \psi} g(x):=\frac{1}{\Gamma\left(\alpha_{1}\right)} \int_{x}^{b_{1}} \psi^{\prime}(\xi)(\psi(\xi)-\psi(x))^{\alpha_{1}-1} g(\xi) d \xi .
$$

If we take $\psi(x)=x$ and $\psi(x)=\ln x$, then we obtain RL and Hadamard fractional integrals, respectively.

The organization of this manuscript is as follows. In Section 1, we give the introduction and preliminaries. Motivated by [35,43], several Ostrowski-type inequalities for the left sided and right sided fractional integrals of a function $g$ with respect to another function $\psi$ are established in Section 2. Illustrative examples are presented in Section 3 to support our results. Section 4 deals with our conclusions.

\section{Main Results}

Below, we will show several new Ostrowski-type inequalities for both left and right sided fractional integrals of a function $g$ with respect to another function $\psi$.

Theorem 2. Assume that the conditions of the Theorem 1 are satisfied. Also, suppose that the function $\psi \in C^{1}(I)$ is increasing and positive monotone, and $\psi^{\prime}(x) \geq 1(\forall x \in I)$. Let $I_{a_{1}^{+}}^{\alpha_{1} ; \psi}$ and $I_{b_{1}^{-}}^{\beta_{1} ; \psi}$ be defined as (2) and (3), respectively. Then the following inequality holds:

$$
\mid\left(\left(\psi\left(b_{1}\right)-\psi(x)\right)^{\beta_{1}}+\left(\psi(x)-\psi\left(a_{1}\right)\right)^{\alpha_{1}}\right) g(x)
$$




$$
\begin{gathered}
-\left(\Gamma\left(\beta_{1}+1\right) I_{b_{1}^{-}}^{\beta_{1} ; \psi} g(x)+\Gamma\left(\alpha_{1}+1\right) I_{a_{1}^{+}}^{\alpha_{1} ; \psi} g(x)\right) \mid \\
\leq M\left(\frac{\beta_{1}}{\beta_{1}+1}\left(\psi\left(b_{1}\right)-\psi(x)\right)^{\beta_{1}+1}+\frac{\alpha_{1}}{\alpha_{1}+1}\left(\psi(x)-\psi\left(a_{1}\right)\right)^{\alpha_{1}+1}\right),
\end{gathered}
$$

where $\alpha_{1}, \beta_{1}>0$ and $x \in\left[a_{1}, b_{1}\right]$.

Proof of Theorem 2. Taking into account that $\psi$ is an increasing and positive monotone function, for $\alpha_{1}>0$ and $\xi \in\left[a_{1}, x\right]$ we get

$$
(\psi(x)-\psi(\xi))^{\alpha_{1}} \leq\left(\psi(x)-\psi\left(a_{1}\right)\right)^{\alpha_{1}} .
$$

Utilizing (5) and the given condition on $g^{\prime}$, we obtain

$$
\int_{a_{1}}^{x}\left(M \psi^{\prime}(\xi)-g^{\prime}(\xi)\right)(\psi(x)-\psi(\xi))^{\alpha_{1}} d \xi \leq\left(\psi(x)-\psi\left(a_{1}\right)\right)^{\alpha_{1}} \int_{a_{1}}^{x}\left(M \psi^{\prime}(\xi)-g^{\prime}(\xi)\right) d \xi
$$

and

$$
\int_{a_{1}}^{x}\left(M \psi^{\prime}(\xi)+g^{\prime}(\xi)\right)(\psi(x)-\psi(\xi))^{\alpha_{1}} d \xi \leq\left(\psi(x)-\psi\left(a_{1}\right)\right)^{\alpha_{1}} \int_{a_{1}}^{x}\left(M \psi^{\prime}(\xi)+g^{\prime}(\xi)\right) d \xi .
$$

If the above integrals are calculated, we obtain the following inequalities, respectively:

$$
\left(\psi(x)-\psi\left(a_{1}\right)\right)^{\alpha_{1}} g(x)-\Gamma\left(\alpha_{1}+1\right) I_{a_{1}^{+}}^{\alpha_{1} ; \psi} g(x) \leq \frac{M \alpha_{1}}{\alpha_{1}+1}\left(\psi(x)-\psi\left(a_{1}\right)\right)^{\alpha_{1}+1}
$$

and

$$
\Gamma\left(\alpha_{1}+1\right) I_{a_{1}^{+}}^{\alpha_{1} ; \psi} g(x)-\left(\psi(x)-\psi\left(a_{1}\right)\right)^{\alpha_{1}} g(x) \leq \frac{M \alpha_{1}}{\alpha_{1}+1}\left(\psi(x)-\psi\left(a_{1}\right)\right)^{\alpha_{1}+1} .
$$

By using (6) and (7), we report the following inequality:

$$
\left|\left(\psi(x)-\psi\left(a_{1}\right)\right)^{\alpha_{1}} g(x)-\Gamma\left(\alpha_{1}+1\right) I_{a_{1}^{+}}^{\alpha_{1} ; \psi} g(x)\right| \leq \frac{M \alpha_{1}}{\alpha_{1}+1}\left(\psi(x)-\psi\left(a_{1}\right)\right)^{\alpha_{1}+1} .
$$

On the other hand, if $\psi$ is an increasing and positive function, for $\xi \in\left[x, b_{1}\right]$ and $\beta_{1}>0$ we get

$$
(\psi(\xi)-\psi(x))^{\beta_{1}} \leq\left(\psi\left(b_{1}\right)-\psi(x)\right)^{\beta_{1}} .
$$

By using (9) and the given condition on $g^{\prime}$, we conclude

$$
\int_{x}^{b_{1}}\left(M \psi^{\prime}(\xi)-g^{\prime}(\xi)\right)(\psi(\xi)-\psi(x))^{\beta_{1}} d \xi \leq\left(\psi\left(b_{1}\right)-\psi(x)\right)^{\beta_{1}} \int_{x}^{b_{1}}\left(M \psi^{\prime}(\xi)-g^{\prime}(\xi)\right) d \xi
$$

and

$$
\int_{x}^{b_{1}}\left(M \psi^{\prime}(\xi)+g^{\prime}(\xi)\right)(\psi(\xi)-\psi(x))^{\beta_{1}} d \xi \leq\left(\psi\left(b_{1}\right)-\psi(x)\right)^{\beta_{1}} \int_{x}^{b_{1}}\left(M \psi^{\prime}(\xi)+g^{\prime}(\xi)\right) d \xi .
$$

If the above integrals are calculated, we obtain the following inequalities, respectively:

$$
\Gamma\left(\beta_{1}+1\right) I_{b_{1}^{-}}^{\beta_{1} ;} g(x)-\left(\psi\left(b_{1}\right)-\psi(x)\right)^{\beta_{1}} g(x) \leq \frac{M \beta_{1}}{\beta_{1}+1}\left(\psi\left(b_{1}\right)-\psi(x)\right)^{\beta_{1}+1}
$$

and

$$
\left(\psi\left(b_{1}\right)-\psi(x)\right)^{\beta_{1}} g(x)-\Gamma\left(\beta_{1}+1\right) I_{b_{1}^{-}}^{\beta_{1} ;} g(x) \leq \frac{M \beta_{1}}{\beta_{1}+1}\left(\psi\left(b_{1}\right)-\psi(x)\right)^{\beta_{1}+1} .
$$


By using (10) and (11), the following inequality will appear:

$$
\left|\left(\psi\left(b_{1}\right)-\psi(x)\right)^{\beta_{1}} g(x)-\Gamma\left(\beta_{1}+1\right) I_{b_{1}^{-}}^{\beta_{1}} g(x)\right| \leq \frac{M \beta_{1}}{\beta_{1}+1}\left(\psi\left(b_{1}\right)-\psi(x)\right)^{\beta_{1}+1} .
$$

So, by utilizing (8) and (12), we obtain (4).

Theorem 3. Let $g: I \rightarrow \mathbb{R}$ be a mapping differentiable in $I^{\circ}$ (the interior of $I$ ) such that $I$ is an interval in $\mathbb{R}$ and $a_{1}, b_{1} \in I^{\circ}, a_{1}<b_{1}$. Assume that the function $\psi \in C^{1}(I)$ is increasing and positive monotone, and $\psi^{\prime}(x) \geq 1(\forall x \in I)$. Also, let $I_{a_{1}^{+}}^{\alpha_{1} ; \psi}$ and $I_{b_{1}^{-}}^{\beta_{1} ; \psi}$ be defined as (2) and (3), respectively. If $m \leq g^{\prime}(t) \leq M$ for $M \geq 0, m \leq 0$ and all $\xi \in\left[a_{1}, b_{1}\right]$, then the following inequalities hold:

$$
\begin{gathered}
\left(\left(\psi(x)-\psi\left(a_{1}\right)\right)^{\alpha_{1}}-\left(\psi\left(b_{1}\right)-\psi(x)\right)^{\beta_{1}}\right) g(x) \\
-\left(\Gamma\left(\alpha_{1}+1\right) I_{a_{1}^{+}}^{\alpha_{1} ; \psi} g(x)-\Gamma\left(\beta_{1}+1\right) I_{b_{1}^{-}}^{\beta_{1} ; \psi} g(x)\right) \\
\leq M\left(\frac{\alpha_{1}}{\alpha_{1}+1}\left(\psi(x)-\psi\left(a_{1}\right)\right)^{\alpha_{1}+1}+\frac{\beta_{1}}{\beta_{1}+1}\left(\psi\left(b_{1}\right)-\psi(x)\right)^{\beta_{1}+1}\right)
\end{gathered}
$$

and

$$
\begin{aligned}
& \left(\left(\psi\left(b_{1}\right)-\psi(x)\right)^{\beta_{1}}-\left(\psi(x)-\psi\left(a_{1}\right)\right)^{\alpha_{1}}\right) g(x) \\
& +\left(\Gamma\left(\alpha_{1}+1\right) I_{a_{1}^{+}}^{\alpha_{1} ; \psi} g(x)-\Gamma\left(\beta_{1}+1\right) I_{b_{1}^{-}}^{\beta_{1} ; \psi} g(x)\right) \\
& \leq-m\left(\frac{\beta_{1}}{\beta_{1}+1}\left(\psi\left(b_{1}\right)-\psi(x)\right)^{\beta_{1}+1}+\frac{\alpha_{1}}{\alpha_{1}+1}\left(\psi(x)-\psi\left(a_{1}\right)\right)^{\alpha_{1}+1}\right),
\end{aligned}
$$

where $\alpha_{1}, \beta_{1}>0$ and $x \in\left[a_{1}, b_{1}\right]$.

Proof of Theorem 3. Using the given comparing conditions on $g^{\prime}$, the proof is similar to one of Theorem 2 . That is, from (5) and by using the given condition on $g^{\prime}$, we conclude

$$
\int_{a_{1}}^{x}\left(M \psi^{\prime}(\xi)-g^{\prime}(\xi)\right)(\psi(x)-\psi(\xi))^{\alpha_{1}} d \xi \leq\left(\psi(x)-\psi\left(a_{1}\right)\right)^{\alpha_{1}} \int_{a_{1}}^{x}\left(M \psi^{\prime}(\xi)-g^{\prime}(\xi)\right) d \xi
$$

and

$$
\int_{a_{1}}^{x}\left(g^{\prime}(\xi)-m \psi^{\prime}(\xi)\right)(\psi(x)-\psi(\xi))^{\alpha_{1}} d \xi \leq\left(\psi(x)-\psi\left(a_{1}\right)\right)^{\alpha_{1}} \int_{a_{1}}^{x}\left(g^{\prime}(\xi)-m \psi^{\prime}(\xi)\right) d \xi .
$$

If the above integrals are calculated, we obtain the following inequalities, namely:

$$
\left(\psi(x)-\psi\left(a_{1}\right)\right)^{\alpha_{1}} g(x)-\Gamma\left(\alpha_{1}+1\right) I_{a_{1}^{+}}^{\alpha_{1} ; \psi} g(x) \leq \frac{M \alpha_{1}}{\alpha_{1}+1}\left(\psi(x)-\psi\left(a_{1}\right)\right)^{\alpha_{1}+1}
$$

and

$$
\Gamma\left(\alpha_{1}+1\right) I_{a_{1}^{+}}^{\alpha_{1} ; \psi} g(x)-\left(\psi(x)-\psi\left(a_{1}\right)\right)^{\alpha_{1}} g(x) \leq-\frac{m \alpha_{1}}{\alpha_{1}+1}\left(\psi(x)-\psi\left(a_{1}\right)\right)^{\alpha_{1}+1} .
$$

On the other hand, by using (9) and the given condition on $g^{\prime}$, we have

$$
\int_{x}^{b_{1}}\left(M \psi^{\prime}(\xi)-g^{\prime}(\xi)\right)(\psi(\xi)-\psi(x))^{\beta_{1}} d \xi \leq\left(\psi\left(b_{1}\right)-\psi(x)\right)^{\beta_{1}} \int_{x}^{b_{1}}\left(M \psi^{\prime}(\xi)-g^{\prime}(\xi)\right) d \xi
$$


and

$$
\int_{x}^{b_{1}}\left(g^{\prime}(\xi)-m \psi^{\prime}(\xi)\right)(\psi(\xi)-\psi(x))^{\beta_{1}} d \xi \leq\left(\psi\left(b_{1}\right)-\psi(x)\right)^{\beta_{1}} \int_{x}^{b_{1}}\left(g^{\prime}(\xi)-m \psi^{\prime}(\xi)\right) d \xi .
$$

If the above integrals are calculated, we obtain the following inequalities, namely:

$$
\Gamma\left(\beta_{1}+1\right) I_{b_{1}^{-}}^{\beta_{1} ; \psi} g(x)-\left(\psi\left(b_{1}\right)-\psi(x)\right)^{\beta_{1}} g(x) \leq \frac{M \beta_{1}}{\beta_{1}+1}\left(\psi\left(b_{1}\right)-\psi(x)\right)^{\beta_{1}+1}
$$

and

$$
\left(\psi\left(b_{1}\right)-\psi(x)\right)^{\beta_{1}} g(x)-\Gamma\left(\beta_{1}+1\right) I_{b_{1}^{-}}^{\beta_{1} ;} g(x) \leq-\frac{m \beta_{1}}{\beta_{1}+1}\left(\psi\left(b_{1}\right)-\psi(x)\right)^{\beta_{1}+1},
$$

respectively. By using (15) and (17), we obtain (13). In addition, by using (16) and (18), we provide (14).

Theorem 4. Let $g: I \rightarrow \mathbb{R}$ be a mapping differentiable in $I^{\circ}$ (the interior of $I$ ) such that $I$ is an interval in $\mathbb{R}$ and $a_{1}, b_{1} \in I^{\circ}, a_{1}<b_{1}$. Assume that the function $\psi \in C^{1}(I)$ is increasing and positive monotone, and $\psi^{\prime}(x) \geq 1(\forall x \in I)$. Also, let $I_{a_{1}^{+}}^{\alpha_{1} ; \psi}$ and $I_{b_{1}^{-}}^{\beta_{1} ; \psi}$ be defined as (2) and (3), respectively. If $m \leq g^{\prime}(t) \leq M$ for $M \geq 0, m \leq 0$ and all $\xi \in\left[a_{1}, b_{1}\right]$, then the following inequalities hold:

$$
\begin{gathered}
\left(\left(\psi(x)-\psi\left(a_{1}\right)\right)^{\alpha_{1}}+\left(\psi\left(b_{1}\right)-\psi(x)\right)^{\beta_{1}}\right) g(x) \\
-\left(\Gamma\left(\alpha_{1}+1\right) I_{a_{1}^{+}}^{\alpha_{1} ; \psi} g(x)+\Gamma\left(\beta_{1}+1\right) I_{b_{1}^{-}}^{\beta_{1} ; \psi} g(x)\right) \\
\leq \frac{M \alpha_{1}}{\alpha_{1}+1}\left(\psi(x)-\psi\left(a_{1}\right)\right)^{\alpha_{1}+1}-\frac{m \beta_{1}}{\beta_{1}+1}\left(\psi\left(b_{1}\right)-\psi(x)\right)^{\beta_{1}+1}
\end{gathered}
$$

and

$$
\begin{aligned}
-\left(\left(\psi\left(b_{1}\right)-\psi(x)\right)^{\beta_{1}}+\left(\psi(x)-\psi\left(a_{1}\right)\right)^{\alpha_{1}}\right) g(x) \\
+\left(\Gamma\left(\alpha_{1}+1\right) I_{a_{1}^{+}}^{\alpha_{1} ; \psi} g(x)+\Gamma\left(\beta_{1}+1\right) I_{b_{1}^{-}}^{\beta_{1} ; \psi} g(x)\right) \\
\leq \frac{M \beta_{1}}{\beta_{1}+1}\left(\psi\left(b_{1}\right)-\psi(x)\right)^{\beta_{1}+1}-\frac{m \alpha_{1}}{\alpha_{1}+1}\left(\psi(x)-\psi\left(a_{1}\right)\right)^{\alpha_{1}+1},
\end{aligned}
$$

where $\alpha_{1}, \beta_{1}>0$ and $x \in\left[a_{1}, b_{1}\right]$.

Proof of Theorem 4. Proof is constructed in the same line as the proof of Theorem 3. By using (15) and (18), we obtain (19). In addition, from (16) and (17), we get (20).

Theorem 5. Suppose that the conditions of the Theorem 2 are satisfied. Also, assume that the function $\psi \in C^{1}(I)$ is increasing and positive monotone, and $\psi^{\prime}(x) \geq 1(\forall x \in I)$. Let $I_{a_{1}^{+}}^{\alpha_{1} ; \psi}$ and $I_{b_{1}^{-}}^{\beta_{1} ; \psi}$ be defined as (2) and (3), respectively. Then the following inequality holds:

$$
\begin{gathered}
\mid\left(\left(\psi\left(b_{1}\right)-\psi(x)\right)^{\beta_{1}} g\left(b_{1}\right)+\left(\psi(x)-\psi\left(a_{1}\right)\right)^{\alpha_{1}} g\left(a_{1}\right)\right) \\
-\left(\Gamma\left(\beta_{1}+1\right) I_{x^{+}}^{\beta_{1} ; \psi} g\left(b_{1}\right)+\Gamma\left(\alpha_{1}+1\right) I_{x^{-}}^{\alpha_{1} ; \psi} g\left(a_{1}\right)\right) \mid \\
\leq M\left(\frac{\beta_{1}}{\beta_{1}+1}\left(\psi\left(b_{1}\right)-\psi(x)\right)^{\beta_{1}+1}+\frac{\alpha_{1}}{\alpha_{1}+1}\left(\psi(x)-\psi\left(a_{1}\right)\right)^{\alpha_{1}+1}\right),
\end{gathered}
$$

where $\alpha_{1}, \beta_{1}>0$ and $x \in\left[a_{1}, b_{1}\right]$. 
Proof of Theorem 5. Recalling $\psi$ is an increasing and positive monotone function, for $\alpha_{1}>0$ and $\xi \in\left[a_{1}, x\right]$ we obtain

$$
\left(\psi(\xi)-\psi\left(a_{1}\right)\right)^{\alpha_{1}} \leq\left(\psi(x)-\psi\left(a_{1}\right)\right)^{\alpha_{1}} .
$$

By using (22) and the given condition on $g^{\prime}$, we have

$$
\int_{a_{1}}^{x}\left(M \psi^{\prime}(\xi)-g^{\prime}(\xi)\right)\left(\psi(\xi)-\psi\left(a_{1}\right)\right)^{\alpha_{1}} d \xi \leq\left(\psi(x)-\psi\left(a_{1}\right)\right)^{\alpha_{1}} \int_{a_{1}}^{x}\left(M \psi^{\prime}(\xi)-g^{\prime}(\xi)\right) d \xi
$$

and

$$
\int_{a_{1}}^{x}\left(M \psi^{\prime}(\xi)+g^{\prime}(\xi)\right)\left(\psi(\xi)-\psi\left(a_{1}\right)\right)^{\alpha_{1}} d \xi \leq\left(\psi(x)-\psi\left(a_{1}\right)\right)^{\alpha_{1}} \int_{a_{1}}^{x}\left(M \psi^{\prime}(\xi)+g^{\prime}(\xi)\right) d \xi .
$$

If the above integrals are calculated, we obtain the following inequalities, respectively:

$$
\Gamma\left(\alpha_{1}+1\right) I_{x^{-}}^{\alpha_{1} ; \psi} g\left(a_{1}\right)-\left(\psi(x)-\psi\left(a_{1}\right)\right)^{\alpha_{1}} g\left(a_{1}\right) \leq \frac{M \alpha_{1}}{\alpha_{1}+1}\left(\psi(x)-\psi\left(a_{1}\right)\right)^{\alpha_{1}+1}
$$

and

$$
\left(\psi(x)-\psi\left(a_{1}\right)\right)^{\alpha_{1}} g\left(a_{1}\right)-\Gamma\left(\alpha_{1}+1\right) I_{x^{-}}^{\alpha_{1} ; \psi} g\left(a_{1}\right) \leq \frac{M \alpha_{1}}{\alpha_{1}+1}\left(\psi(x)-\psi\left(a_{1}\right)\right)^{\alpha_{1}+1} .
$$

By utilizing (23) and (24), the following inequality holds:

$$
\begin{aligned}
\left|\left(\psi(x)-\psi\left(a_{1}\right)\right)^{\alpha_{1}} g\left(a_{1}\right)-\Gamma\left(\alpha_{1}+1\right) I_{x^{-}}^{\alpha_{1} ; \psi} g\left(a_{1}\right)\right| & \\
& \leq \frac{M \alpha_{1}}{\alpha_{1}+1}\left(\psi(x)-\psi\left(a_{1}\right)\right)^{\alpha_{1}+1} .
\end{aligned}
$$

Using the fact that $\psi$ is an increasing and positive monotone function, for $\xi \in\left[x, b_{1}\right]$ and $\beta_{1}>0$ we get

$$
\left(\psi\left(b_{1}\right)-\psi(\xi)\right)^{\beta_{1}} \leq\left(\psi\left(b_{1}\right)-\psi(x)\right)^{\beta_{1}} .
$$

By using (26) and the given condition on $g^{\prime}$, we have

$$
\int_{x}^{b_{1}}\left(M \psi^{\prime}(\xi)-g^{\prime}(\xi)\right)\left(\psi\left(b_{1}\right)-\psi(\xi)\right)^{\beta_{1}} d \xi \leq\left(\psi\left(b_{1}\right)-\psi(x)\right)^{\beta_{1}} \int_{x}^{b_{1}}\left(M \psi^{\prime}(\xi)-g^{\prime}(\xi)\right) d \xi
$$

and

$$
\int_{x}^{b_{1}}\left(M \psi^{\prime}(\xi)+g^{\prime}(\xi)\right)\left(\psi\left(b_{1}\right)-\psi(\xi)\right)^{\beta_{1}} d \xi \leq\left(\psi\left(b_{1}\right)-\psi(x)\right)^{\beta_{1}} \int_{x}^{b_{1}}\left(M \psi^{\prime}(\xi)+g^{\prime}(\xi)\right) d \xi .
$$

If the above integrals are calculated, we obtain the following inequalities, respectively:

$$
\left(\psi\left(b_{1}\right)-\psi(x)\right)^{\beta_{1}} g\left(b_{1}\right)-\Gamma\left(\beta_{1}+1\right) I_{x^{+}}^{\beta_{1} ; \psi} g\left(b_{1}\right) \leq \frac{M \beta_{1}}{\beta_{1}+1}\left(\psi\left(b_{1}\right)-\psi(x)\right)^{\beta_{1}+1}
$$

and

$$
\Gamma\left(\beta_{1}+1\right) I_{x_{1}^{+}}^{\beta_{1} ;} g\left(b_{1}\right)-\left(\psi\left(b_{1}\right)-\psi(x)\right)^{\beta_{1}} g\left(b_{1}\right) \leq \frac{M \beta_{1}}{\beta_{1}+1}\left(\psi\left(b_{1}\right)-\psi(x)\right)^{\beta_{1}+1} .
$$

By making use of (27) and (28), the following inequality holds:

$$
\left|\left(\psi\left(b_{1}\right)-\psi(x)\right)^{\beta_{1}} g\left(b_{1}\right)-\Gamma\left(\beta_{1}+1\right) I_{x^{+}}^{\beta_{1} ; \psi} g\left(b_{1}\right)\right| \leq \frac{M \beta_{1}}{\beta_{1}+1}\left(\psi\left(b_{1}\right)-\psi(x)\right)^{\beta_{1}+1} .
$$

So, from (25) and (29), we obtain (21). 
Corollary 1. If $\beta_{1}=\alpha_{1}$ in Theorem 2, then the following fractional Ostrowski inequality holds:

$$
\begin{gathered}
\mid\left(\left(\psi\left(b_{1}\right)-\psi(x)\right)^{\alpha_{1}}+\left(\psi(x)-\psi\left(a_{1}\right)\right)^{\alpha_{1}}\right) g(x) \\
-\Gamma\left(\alpha_{1}+1\right)\left(I_{b_{1}^{-}}^{\alpha_{1} ; \psi} g(x)+I_{a_{1}^{+}}^{\alpha_{1} ; \psi} g(x)\right) \mid \\
\leq \frac{M \alpha_{1}}{\alpha_{1}+1}\left(\left(\psi\left(b_{1}\right)-\psi(x)\right)^{\alpha_{1}+1}+\left(\psi(x)-\psi\left(a_{1}\right)\right)^{\alpha_{1}+1}\right),
\end{gathered}
$$

where $\alpha_{1}>0$ and $x \in\left[a_{1}, b_{1}\right]$.

Corollary 2. If $\alpha_{1}=\beta_{1}=1$ and $\psi(x)=x$, then we lead to the Ostrowski inequality (1).

Corollary 3. If $\alpha_{1}=\beta_{1}$ in Theorem 5, then we obtain the following fractional Ostrowski inequality:

$$
\begin{gathered}
\mid\left(\left(\psi\left(b_{1}\right)-\psi(x)\right)^{\alpha_{1}} g\left(b_{1}\right)+\left(\psi(x)-\psi\left(a_{1}\right)\right)^{\alpha_{1}} g\left(a_{1}\right)\right) \\
-\Gamma\left(\alpha_{1}+1\right)\left(I_{x^{+}}^{\alpha_{1} ; \psi} g\left(b_{1}\right)+I_{x^{-}}^{\alpha_{1} ; \psi} g\left(a_{1}\right)\right) \mid \\
\leq \frac{M \alpha_{1}}{\alpha_{1}+1}\left(\left(\psi\left(b_{1}\right)-\psi(x)\right)^{\alpha_{1}+1}+\left(\psi(x)-\psi\left(a_{1}\right)\right)^{\alpha_{1}+1}\right),
\end{gathered}
$$

where $\alpha_{1}>0$ and $x \in\left[a_{1}, b_{1}\right]$.

Remark 1. If we take $\psi(x)=x$, then Theorem 2, Theorem 3, and Theorem 5 reduce to Theorem 1.2-Theorem 1.4 in Farid [35], respectively. But, in [35], $-m$ should be $M$ in the first inequality in Theorem 1.3. Also, $M$ should be $-m$ in the second inequality.

Remark 2. After following the steps of the proof of Theorem 2 with $\psi(x)=x$ and $\alpha_{1}=\beta_{1}=1$, an alternative proof of the Ostrowski inequality is obtained (see [37]).

\section{Examples}

In this section, we support our main results by presenting two examples.

Example 1. Let $\alpha_{1}=0.5, \beta_{1}=2.2, \psi(x)=e^{x}, g(x)=\sin x$ and $\left[a_{1}, b_{1}\right]=[0, \pi]$. Then, we obtain $\left|g^{\prime}(x)\right|=|\cos x| \leq 1$, that is, $M=1$. Also, $\psi(x)=e^{x}$ is an increasing continuous derivative and positive monotone function with $\psi^{\prime}(x)=e^{x} \geq 1$ for all $x \in[0, \pi]$. Then, using Theorem 2, for $[0, \pi]$ we obtain the following Ostrowski type inequality:

$$
\begin{array}{r}
\left|\left(\left(e^{\pi}-e^{x}\right)^{2.2}+\left(e^{x}-1\right)^{0.5}\right) \sin x-\left(\Gamma(3.2) I_{\pi^{-}}^{2.2 ; \psi} \sin x+\Gamma(1.5) I_{0^{+}}^{0.5 ; \psi} \sin x\right)\right| \\
\leq \frac{11}{16}\left(e^{\pi}-e^{x}\right)^{3.2}+\frac{1}{3}\left(e^{x}-1\right)^{1.5}
\end{array}
$$

Example 2. Let $\alpha_{1}=0.5, \beta_{1}=2.2, \psi(x)=6 \sqrt{x+2}, g(x)=(x-1)^{2}$ and $\left[a_{1}, b_{1}\right]=[0,2]$. Then, we get $g^{\prime}(x)=2(x-1)$. Let $m=-2$ and $M=2$. Also, $\psi(x)=6 \sqrt{x+2}$ is an increasing continuous derivative and positive monotone function with $\psi^{\prime}(x)=\frac{3}{\sqrt{x+2}} \geq 1$ for all $x \in I=[0,2]$.Then, using Theorem 3 , for $x \in[0,2]$ we obtain the following Ostrowski type inequality:

$$
\begin{gathered}
\left((6 \sqrt{x+2}-6 \sqrt{2})^{0.5}-(12-6 \sqrt{x+2})^{2.2}\right)(x-1)^{2}-\left(\Gamma(1.5) I_{0^{+}}^{0.55 \psi}(x-1)^{2}-\Gamma(3.2) I_{2^{-}}^{2.2 ; \psi}(x-1)^{2}\right) \\
\leq 2\left(\frac{1}{3}(6 \sqrt{x+2}-6 \sqrt{2})^{1.5}+\frac{11}{16}(12-6 \sqrt{x+2})^{3.2}\right)
\end{gathered}
$$


and

$$
\begin{gathered}
\left((12-6 \sqrt{x+2})^{2.2}-(6 \sqrt{x+2}-6 \sqrt{2})^{1.5}\right)(x-1)^{2}+\left(\Gamma(1.5) I_{0^{+}}^{0.5 ; \psi}(x-1)^{2}-\Gamma(3.2) I_{2^{-}}^{2.2 ; \psi}(x-1)^{2}\right) \\
\leq 2\left(\frac{11}{16}(6 \sqrt{2}-6 \sqrt{x+2})^{3.2}+\frac{1}{3}(6 \sqrt{x+2}-6 \sqrt{2})^{1.5}\right)
\end{gathered}
$$

\section{Conclusions}

Studies involving integral inequalities play an important role in several areas of science and engineering. During recent years, such inequalities have been generalized and developed by many researchers. Ostrowski inequalities have a great importance while studying the error bounds of different numerical quadrature rules, for example the midpoint rule, Simpson's rule, the trapezoidal rule and other generalized Riemann types. In this paper, by generalizing the inequalities in [35], we proposed, within four theorems and their related corollaries, several new Ostrowski-type integral inequalities for the left and right sided fractional integrals of a function $g$ with respect to another function $\psi$. Finally, we investigated in detail two examples to show the reported results.

Author Contributions: All authors contributed to each part of this work equally, and they all read and approved the final manuscript.

Funding: This research received no external funding.

Acknowledgments: The authors would like to thank to the referees for their useful comments and remarks.

Conflicts of Interest: The authors declare no conflicts of interest.

\section{References}

1. Leibniz, G.W. Letter from Hanover, Germany to G.F.A L'Hospital, September 30, 1695. In Leibniz Mathematische Schriften; Olms-Verlag: Hildesheim, Germany, 1962; pp. 301-302.

2. Leibniz, G.W. Letter from Hanover, Germany, to Johann Bernoulli, December 28, 1695 . In Leibniz Mathematische Schriften; Olms-Verlag: Hildesheim, Germany, 1962; p. 226.

3. Leibniz, G.W. Letter from Hanover, Germany, to John Wallis, May 30, 1697. In Leibniz Mathematische Schriften; Olms-Verlag: Hildesheim, Germany, 1962; p. 25.

4. Kilbas, A.A.; Srivastava, H.M.; Trujillo, J.J. Theory and applications of fractional differential equations. In North-Holland Mathematics Studies; Elsevier: Amsterdam, The Netherlands, 2006; p. 204.

5. Samko, S.G.; Kilbas, A.A.; Marichev, O.I. Fractional Integrals and Derivatives; Gordon and Breach: Yverdon, Switzerland, 1993.

6. Atanackovic, T.M.; Pilipovic, S.; Stankovic, B.; Zorica, D. Fractional Calculus with Applications in Mechanics: Vibrations and Diffusion Processes; Wiley: London, UK; Hoboken, NJ, USA, 2014.

7. Bandle, C.; Gilányi, A.; Losonczi, L.; Páles, Z.; Plum, M. Inequalities and Applications: Conference on Inequalities and Applications, Noszvaj (Hungary), September 2007; Springer: Berlin/Heidelberg, Germany, 2008; p. 157.

8. Bainov, D.D.; Simeonov, P.S. Integral Inequalities and Applications; Springer: Berlin/Heidelberg, Germany, 2013; p. 57.

9. Corlay, S.; Lebovits, J.; Véhel, J.L. Multifractional stochastic volatility models. Math. Finance 2014, 24, $364-402$. [CrossRef]

10. Herrmann, R. Fractional Calculus: An Introduction for Physicists; World Scientific Publishing Company: Singapore, 2011.

11. Magin, R.L.; Ingo, C; Colon-Perez, L.; Triplett, W.; Mareci, T.H. Characterization of anomalous diffusion in porous biological tissues using fractional order derivatives an, entropy. Microporous Mesoporous Mater. 2013, 178, 39-43. [CrossRef] [PubMed]

12. Magin, R.L. Fractional calculus models of complex dynamics in biological tissues. Comput. Math. Appl. 2010, 59, 1586-1593. [CrossRef]

13. Meral, F.; Royston, T.; Magin, R. Fractional calculus in viscoelasticity: An experimental study. Commun. Nonlinear Sci. Numer. Simul. 2010, 15, 939-945. [CrossRef] 
14. Silva Costa, F.; Soares, J.C.S.; Gomez Plata, A.R.; Capelas de Oliveira, E. On the fractional Harry Dym equation. Comput. Appl. Math. 2018, 37, 2862-2876. [CrossRef]

15. Silva Costa, F.; Contharteze Grigoletto, E.; Vaz Jr, J.; Capelas de Oliveira, E. Slowing-down of neutrons: A fractional model. Commun. Appl. Ind. Math. 2015, 6. [CrossRef]

16. Aljinević, A.A. Montgomery identity and Ostrowski type inequalities for Riemann-Liouville fractional integral. J. Math. Vol. 2014, 503195. [CrossRef]

17. Dragomir, S.S. Ostrowski type inequalities for Riemann-Liouville fractional integrals of bounded variation, Hölder and Lipschitzian functions. RGMIA Res. Rep. Coll. 2017, 20, 48.

18. Dragomir, S.S. Ostrowski type inequalities for generalized Riemann-Liouville fractional integrals of functions with bounded variation. RGMIA Res. Rep. Coll. 2017, 20, 58.

19. Dragomir, S.S. Further Ostrowski and Trapezoid type inequalities for Riemann-Liouville fractional integrals of functions with bounded variation. RGMIA Res. Rep. Coll. 2017, 20, 84.

20. Anastassiou, G.M.; Hooshmandasl, R.; Ghasemi, A.; Moftakharzahed, F. Montgomery identities for fractional integrals and related fractional inequalities. J. Inequal. Pure Appl. Math. 2009, 10, 97.

21. Chen, F. Extensions of the Hermite-Hadamard inequality for convex functions via fractional integrals. J. Math. Inequal. 2016, 10, 75-81. [CrossRef]

22. Chen, H.; Katugampola, U.N. Hermite-Hadamard and Hermite-Hadamard-Fejér type inequalities for generalized fractional integrals. J. Math. Anal. Appl. 2013, 446, 1274-1291. [CrossRef]

23. Iqbal, S.; Krulić, K.; Pečarić, J. Weighted Hardy-type inequalities for monotone convex functions with some applications. Fract. Differ. Calc. 2013, 3, 31-53. [CrossRef]

24. Iqbal, S.; Krulić, K.; Pečarić, J. On refined Hardy-type inequalities with fractional integrals and fractional derivatives. Math. Slovaca 2014, 64, 879-892. [CrossRef]

25. Iqbal S, Krulić K, Pečarić J. On a new class of Hardy-type inequalities with fractional integrals and fractional derivatives. Rad Hazu. Mathematičke Znanosti 2014, 18=519, 91-106.

26. Iqbal, S.; Pečarić, J.; Samraiz, M.; Tomovski, Z. Hardy-type inequalities for generalized fractional integral operators. Tbilisi Math. J. 2017, 10, 75-90. [CrossRef]

27. Iqbal, S.; Pečarić, J.; Samraiz, M.; Tomovski, Z. On some Hardy-type inequalities for fractional calculus operators. Banach J. Math. Anal. 2017, 11, 438-457. [CrossRef]

28. Jain, R.; Pathan, M.A. On Weyl fractional integral operators. Tamkang J. Math. 2004, 35, 169-173. [CrossRef]

29. Nasibullin, R. Hardy-type inequalities for fractional integrals and derivatives of Riemann-Liouville. Lobacherskii J. Math. 2017, 38, 709-718. [CrossRef]

30. Sarıkaya, M.Z.; Budak, H. New inequalities of Opial type for conformable fractional integrals. Turk. J. Math. 2017, 41, 1164-1173. [CrossRef]

31. Set, E.; İscan, I.; Sarıkaya, M.Z.S.; Özdemir, M.E. On new inequalities of Hermite-Hadamard Fejér type for convex functions via fractional integrals. Appl. Math. Comput. 2015, 259, 875-881. [CrossRef]

32. Wang, J.; Li, X.; Fekan, M.; Zhou, Y. Hermite-Hadamard-type inequalities for Riemann-Liouville fractional integrals via two kinds of convexity. Appl. Anal. 2013, 92, 2241-2253. [CrossRef]

33. Ostrowski, A. Über die Absolutabweichung einer differentiierbaren Funktion von ihrem Integralmittelwert. Comment. Math. Helv. 1937, 10, 226-227. [CrossRef]

34. Mitrinovic, D.S.; Pecaric, J.; Fink, A.M. Inequalities Involving Functions and Their Integrals and Derivatives; Mathematics and its Applications (East European Series), 53, Kluwer Academic Publishers: Dortrecht, The Netherlands, 1991.

35. Farid, G. Some new Ostrowski type inequalities via fractional integrals. Int. J. Anal. Appl. 2017, 14, 64-68.

36. Alomari, M.; Darus, M. Some Ostrowski type inequalities for convex functions with applications. RGMIA 2010, 13, 3 .

37. Farid, G. Straightforward proofs of Ostrowski inequality and some related results. Int. J. Anal. 2016, 2016, 3918483. [CrossRef]

38. Yue, Hu. Ostrowski inequality for fractional integrals and related fractional inequalities. Transylv. J. Math. Mech. 2013, 5, 85-89.

39. Khan, M.A.; Begum, S.; Khurshid, Y.; Chu, Y.-M. Ostrowski type inequalities involving conformable fractional integral. J. Inequal. Appl. 2018, 2018, 70. [CrossRef]

40. Liu, W. Some Ostrowski type inequalities via Riemann-Liouville fractional integrals for $h$-convex functions. J. Comput. Anal. Appl. 2012, 16, 998-1004. 
41. Set, E. New inequalities for Ostrowski type for mappings whose derivatives are s-convex in the second sense via fractional integrals. Comput. Math. Appl. 2012, 63, 1147-1154. [CrossRef]

42. Tunç, M. Ostrowski type inequalities via $h$-convex functions with applications for special means. J. Inequal. Appl. 2013, 2013, 326. [CrossRef]

43. Vanterler da C. Sousa, J.; Capelas de Oliveira, E. On the $\psi$-Hilfer fractional derivative. Commun. Nonlinear Sci. Numer. Simul., 2018, 60, 72-91. [CrossRef]

44. Vanterler da C. Sousa, J.; Capelas de Oliveira, E. A Gronwall inequality and the Cauchy-type problem by means of $\psi$ - Hilfer operator. Differ. Equ. Appl. 2019 11, 87-106. [CrossRef]

45. Yaldız, H.; Set, E. Some new Ostrowski type inequalities for generalized fractional integrals. AIP Conf. Proc. 2018, 1991, 020018. [CrossRef]

46. Yıldırım, H.; Kırtay, Z. Ostrowski inequality for generalized fractional integral and related inequalities. Malaya J. Mat. 2014, 2, 322-329.

47. Yıldız, Ç.; Özdemir, M.E.; Sarıkaya, M.Z. New generalizations of Ostrowski-Like type inequalities for fractional integral. Kyungpook Math. J. 2016, 56, 161-172. [CrossRef]

(C) 2019 by the authors. Licensee MDPI, Basel, Switzerland. This article is an open access article distributed under the terms and conditions of the Creative Commons Attribution (CC BY) license (http:/ / creativecommons.org/licenses/by/4.0/). 